\title{
Environmentally acquired chemical camouflage affects Pieris brassicae L. host plant selection and orientation behaviour of a larval parasitoid
}

\author{
Thuy Nga T. Bui ${ }^{1}$ [D $\cdot$ Sari J. Himanen ${ }^{2}$ Jarmo K. Holopainen ${ }^{1}$
}

Received: 14 October 2020 / Accepted: 28 March 2021 / Published online: 19 April 2021

(c) The Author(s) 2021

\begin{abstract}
Environmentally acquired chemical camouflage is a phenomenon, where a plant growing close to a strong volatile organic compound (VOC) emitter will adsorb and re-emit the VOCs produced by the neighbouring plant. The re-emitted volatile bouquet may resemble more the VOC composition of the neighbour than plant's own typical odour, and thus act as chemical camouflage against insect detection, potentially simultaneously providing associational resistance towards herbivory. We exposed a pest-sensitive horticultural crop, Brassica oleracea var. italica (broccoli) cv. Lucky, to the volatiles emitted by Rhododendron tomentosum [RT] twigs and assessed the host selection by ovipositing females and larval instars of the major caterpillar pest Pieris brassicae between RT-exposed and control plants. Potential impact of RT exposure on herbivore natural enemies was studied using behavioural tests with a parasitoid wasp Cotesia glomerata. P. brassicae females laid significantly less eggs and egg clusters were fewer on RT-exposed plants at both night-time $\left(6{ }^{\circ} \mathrm{C}\right)$ and daytime $\left(22^{\circ} \mathrm{C}\right)$ temperatures. Larvae preferred leaves from control plants over RT-exposed plants at both temperatures. Preceding RT-exposure did not disturb orientation of parasitoid wasp Cotesia glomerata females towards $B$. oleracea plants damaged by its host $P$. brassicae. However, host-damaged control plants were favoured by the parasitoid over RT-exposed, host-damaged plants. Our results suggest that companion plant based chemical camouflage as a mechanism of pest suppression could be developed as an additional tool for the integrated pest management toolbox in agriculture.
\end{abstract}

Keywords Plant-plant volatile cues $\cdot$ Semivolatiles $\cdot$ Passive volatile adsorption $\cdot$ Orientation behaviour $\cdot$ Indirect defence $\cdot$ Associational resistance

\section{Introduction}

The high diversity of plant secondary metabolites (PSMs) with a current estimate of 200,000 specific chemical compounds (Kessler and Kalske 2018) is explained by the need of plants to protect themselves against various biotic and abiotic stressors (Blande et al. 2014; Julkunen-Tiitto et al. 2015; Kalske et al. 2019; Loreto and Schnitzler 2010; Moreira

Handling Editor: Miriama Malcicka.

Thuy Nga T. Bui

thuynga.buithi@uef.fi

1 Department of Environmental and Biological Sciences, University of Eastern Finland, P.O. Box 1627,

70211 Kuopio, Finland

2 Natural Resources Institute Finland (Luke), Natural Resources, Plant Health, Lönnrotinkatu 7, 50100 Mikkeli, Finland et al. 2018). In selection breeding of edible crop plants, the PSMs that are toxic or distasteful for humans have been reduced (Moreira et al. 2018), but genotypes rich with the specific PSMs that maintain the resistance against pests and pathogens, have been favoured (Wink 1988). In the Brassicaceae family, glucosinolates are the major PSMs that provide protection against polyphagous herbivores (Agut et al. 2018). Glucosinolate concentrations have been reduced in breeding of edible crop plants, but even low concentrations of those acts as attractants for numerous specialist Brassicaceae crop herbivores (Sontowski et al. 2019).

Since various secondary metabolites are known to be important for insect olfaction and host location, some PSMs might also be useful for protection against Brassicaceae specialist herbivores (Talekar and Shelton 1993). These could be e.g., higher concentration of flavonoid metabolites in host plant tissue (Onkokesung et al. 2014) or volatile terpenoids produced by neighbouring plant and adsorbed on the leaf surface of the host plant (Himanen et al. 2015). Furthermore, 
the lowest energy cost for chemical defence could be in a case when the chemicals produced by other plants can be used to reduce the risk of attack by herbivores e.g., by adsorbing distinctive volatile organic compounds (VOCs) of neighbouring plant species (Himanen et al. 2010; Kessler and Kalske 2018).

In addition to plant-herbivore interactions, the plant VOCs play an important role in plant-plant interactions in ecosystems (Blande et al. 2010) and in plant's attraction of natural enemies of insect herbivores (Dicke et al. 2009; Stenberg et al. 2015; Turlings et al. 1990). Furthermore, specific VOCs emitted by a specific plant species are important signals that keep polyphagous herbivores and the specialist herbivores of other plant species away (Agut et al. 2018). Plants may have different strategies to avoid specialist herbivores to find the right host plant with the host-typical bouquet of VOCs. According to Kessler and Kalske (2018) these may include: (1) release of typical herbivore-induced VOCs which might indicate to other herbivores that plant is already occupied by herbivores; (2) reduce VOC emissions among other plants to become chemically less apparent; (3) release of a VOC which may disturb sensing of other host plant VOCs i.e. increase of chemical noise; and (4) releasing volatile cues that mimic other plant VOCs. There is still a lack of evidence of plant capacity to mimic VOC bouquet typical for other plant species (Kessler and Kalske 2018). However, mimicking another plant species VOC profile could be also based on adsorbed volatiles produced by another plant species (Himanen et al. 2010; Mofikoya et al. 2018a) or other exogenous source (Camacho-Coronel et al. 2020). Kessler and Kalske (2018) considered this as environmentally acquired chemical camouflage (EACC), i.e., a plant growing close to a strong VOC emitter will adsorb and reemit VOCs produced the neighbouring plant, might act as mimicking the chemical cues of a more defended or chemically differently defended plants.

Plant signalling via herbivore-induced volatiles to activate chemical defences in external parts of the damaged plant or in the intact receiver plant have been documented in various studies in recent years as summarised by Heil (2014). Less is known about biological effects accumulation of plant VOCs in surrounding soil (Barney et al. 2009) and on neighbouring plant surfaces (Himanen et al. 2010; Mofikoya et al. 2018b, 2019) or leaf surface vax (CamachoCoronel et al. 2020; Li and Blande 2015). Accumulation of volatile monoterpenes released by a neighbouring plant in soil matrix in high concentration prevents seed germination (Santonja et al. 2019) and growth of other plants (Barney et al. 2009; Santonja et al. 2019). In addition, uptake of high atmospheric concentrations of isoprene (Ormeño et al. 2020) and monoterpenes (Copolovici et al. 2005; Noe et al. 2007) by growing plants via stomata and release back to atmosphere is reported (Copolovici et al. 2005; Mofikoya et al. 2018b; Niinemets et al. 2014; Noe et al. 2007). Semivolatile sesquiterpenes are sticky and can become adsorbed on various surfaces such as glass (Schaub et al. 2010) and plant wax layer (Camacho-Coronel et al. 2020; Joensuu et al. 2016; $\mathrm{Li}$ and Blande 2015) but also on the foliage of conspecific (Li and Blande 2015) and heterospecific (Himanen et al. 2010; Mofikoya et al. 2018b) neighbouring plants and could be released back to the atmosphere at higher temperatures (Himanen et al. 2010; Mofikoya et al. 2018b; Schaub et al. 2010).

Rhododendron tomentosum Harmaja (previously: Ledum palustre L.) is commonly known, highly recognizable aromatic plant species with English names such as wild rosemary, marsh tea or marsh rosemary, although it belongs to the Ericacea plant family. It is a subarctic and boreal fragrant shrub with circumpolar distribution and growing mostly in peatlands and forest understory (Dampc and Luczkiewicz 2013). Particularly European provenances (Raal et al. 2014; Zhao et al. 2016) of the species are rich with species specific volatiles and semi-volatile terpenoids in essential oil stored in glandular trichomes on surface of stems and leaves (Dampc and Luczkiewicz 2013; Mofikoya et al. 2018b; Zhao et al. 2016). Major volatile compounds in distilled essential oil and volatile emission are semi-volatile sesquiterpene alcohols palustrol and ledol, sesquiterpene ledene and monoterpene myrcene. Proportion of palustrol in total extracted essential oil (Raal et al. 2014) or in total emission (Himanen et al. 2010) can exceed 50\%. The essential oil has shown repellent effects on blood feeding mosquitoes (Jaenson et al. 2006) and ticks (Jaenson et al. 2005) as well as herbivorous leaf beetles and bark-boring weevils (Egigu et al. 2011). The composition of $R$. tomentosum VOCs among Northern European plant species makes it easy to track the deposition of RT emissions on other plants (Himanen et al. 2010, 2015; Mofikoya et al. 2018a).

There are only few studies of environmentally acquired chemical camouflage yet, with very few plant and herbivore species tested. So far, and to our knowledge, the only studies that relate plant uptake and release of neighbouring plant VOCs to herbivory, i.e., showing EACC, have been conducted with VOCs of $R$. tomentosum (henceforth referred to as RT). Himanen et al. (2010) described the adherence of (RT) semi-volatile compounds and their release on the leaf surfaces of birch species (Betula spp.). In another study, adherence of RT volatiles from detached RT branches on white cabbage was shown (Himanen et al. 2015). Moreover, after a cold night, some of the $R$. tomentosum VOCs were more abundant in birch emissions than typical birch volatiles. During the day adhered compound were reemitted, and in the afternoon when temperature changed from 20 to $25^{\circ} \mathrm{C}$ - RT volatiles were still detectable, but with low rates and not among dominant VOCs (Himanen et al. 2010). In the biotests with the diamondback moth, Plutella xylostella 
(L.) (Lepidoptera: Plutellidae), RT-exposed white cabbage seedlings were less susceptible to moth oviposition at both night-time $\left(12{ }^{\circ} \mathrm{C}\right)$ and daytime $\left(22{ }^{\circ} \mathrm{C}\right)$ temperatures, and the moth larvae favoured unexposed control leaves and did more feeding damage on control than on RT-exposed leaves. More importantly, RT-exposure did not interfere with orientation of parasitoid Cotesia vestalis on P. xylostella-damaged foliage (Himanen et al. 2015).

Recent studies such as Himanen et al. (2010) have shown that, when RT and birch (Betula spp.) plants were grown in natural mixed field and peatland ecosystems, birch leaves could adsorb and re-release the specific arthropod-repelling signals such as ledene, ledol and palustrol produced by RT plants. When the distance between two plant species was $<$ $5 \mathrm{~m}$, birches neighbouring RT released a much higher ledene concentration. Similarly, $R$. tomentosum -neighbouring $B$. pendula had also increased emission of a sesquiterpene, alpha-humulene. Terpenes are the most important semivolatile compounds in this mechanism.

This study is aimed to evaluate if exposure of Brassica plants on $R$. tomentosum volatiles will provide protection against the chewing foliar insect herbivore $P$. brassicae as shown earlier by Himanen et al. (2015) with P. xylostella. Pieris species are widely spread and their caterpillars damage various Brassicacea crops globally (Feber et al. 1997), so better knowledge of the possibilities for Pieris biocontrol with natural mechanisms interfering with its olfaction to host such as aromatic VOCs or companion planting will be valuable. Also, it is important to know, how a natural biocontrol agent of Pieris species endoparasitoid Cotesia glomerata L. (Hymenoptera: Braconidae) (Driesche 2008; Takabayashi et al. 1998) is influenced by exogenously acquired plant volatiles on host plant surface. Its preferred hosts are young larvae of pierid butterfly species including $P$. brassicae (Brodeur et al. 1996; Harvey et al. 2003; Martijn Bezemer et al. 2010). Parasitoid C. glomerata in the fields can disperse quickly (Wanner et al. 2006) and can be found in meadow habitats (Benson et al. 2003). If a potential VOCbased biocontrol strategy would interfere with the olfactory host location of pest natural enemies, the strategy would be less effective, as being strongly compromised by the reduced natural biological control.

Thus, to understand the overall responses of a plant-herbivore-natural enemy complex to environmentally acquired chemical camouflage, we exposed B. oleracea var. italica (broccoli) plants to the volatiles of RT branches, followed by assessing host selection between RT-exposed and control plants by $P$. brassicae larvae, oviposition by $P$. brassicae females and orientation behaviour of the larval endoparasitoid $C$. glomerata. Younger 2nd instar and older 4th instar $P$. brassicae larvae were used in host selection, because additional terpenoids could be stronger repellent in early instar larvae than late in instar larvae (Rossiter et al. 1986).
We did not include VOC-analysis in this study, because recent studies (Himanen et al. 2015; Mofikoya et al. 2018a) in our laboratory have reported the major RT-emitted volatiles accumulated on the surface of $B$. olearacae plants. The major RT VOCs recovered from the foliage of $B$. oleraecea plants when exposed to the same RT provenance as used in this study were monoterpenes (myrcene and neoallo-ocimene) and sesquiterpenoids (aromadendrene, $\alpha$-gurjunene, isoledene, ledene and palustrol) (Mofikoya et al. 2018b; Fig. 1).

\section{Materials and methods}

\section{Plants and herbivores}

Plant material. B. oleracea var. italica (broccoli) cv. Lucky seedlings were propagated at the Research Garden of the University of Eastern Finland, Kuopio campus. Seedlings were cultivated from seed in 0.661 pots (four plants per each pot in a greenhouse). Pots filled with mixture 2:1:1 of fertilised compost, NPK 100:30:200 $\mathrm{mg}^{-1}$ : Sphagnum peat (B2) peat NPK 110:40:220 $\mathrm{mg} \mathrm{l}^{-1}$ and sand) were grown under greenhouse conditions (at temperature $20 / 16^{\circ} \mathrm{C}$ day/ night). Broccoli plants were utilized for experiments at around 3 weeks of age for oviposition experiments and 4 weeks of age for larval choice experiment (in order to have more leaf mass).

For VOC exposure experiments, $R$. tomentosum (RT) branches (about $25-30 \mathrm{~cm}$ high) were collected from a natural habitat of Suonenjoki in Finland (at $62^{\circ} 38^{\prime} 42.683^{\prime \prime} \mathrm{N}$, $27^{\circ} 3^{\prime} 55.383^{\prime \prime} \mathrm{E}$ ), and then kept at $+6^{\circ} \mathrm{C}$ in the cold room before use in the B. oleracea exposure treatments in fume hoods and temperature-controlled plant exposure room.

\section{Insects for experiments}

Eggs of P. brassicae (Lepidoptera: Pieridae) were originally derived from the cultures at the Entomology Laboratory of Wageningen University, the Netherlands. Laboratory stocks of $P$. brassicae larvae and adults that were used for the experiments originated from laboratory populations reared from those eggs in Department of Environmental and Biological Sciences, University of Eastern Finland. Our stock larvae were an insect culture maintained on Brussels sprout plants (B. oleracea var. gemmifera L. cultivar Cyrus) in a room with controlled temperature at $20 \pm 2{ }^{\circ} \mathrm{C}$, with RH $50-70 \%$ (Khaling et al. 2015). Moreover, to establish a P. brassicae insect population for these experiments, females of this stock which were allowed to oviposit were maintained on broccoli (B. oleracea var. italica) plants $\left(20-25^{\circ} \mathrm{C}\right.$ temperature and 16L: 8D photoperiod) in plant growth chambers. 
Fig. 1 Relative proportion of RT VOCs recovered from Brassica oleracea foliage after exposure to the Suonenjoki RT provenance (data from Mofikoya et al. 2018a, b). The same RT provenance was used in the insect experiment reported this study. To better describe the type of compound detected. Sector fills: black $=$ volatiles produce by Brassica plant; white $=$ RT sesquiterpene alcohol; vertical dash $=$ RT sesquiterpenes; horizontal dash $=$ RT monoterpenes

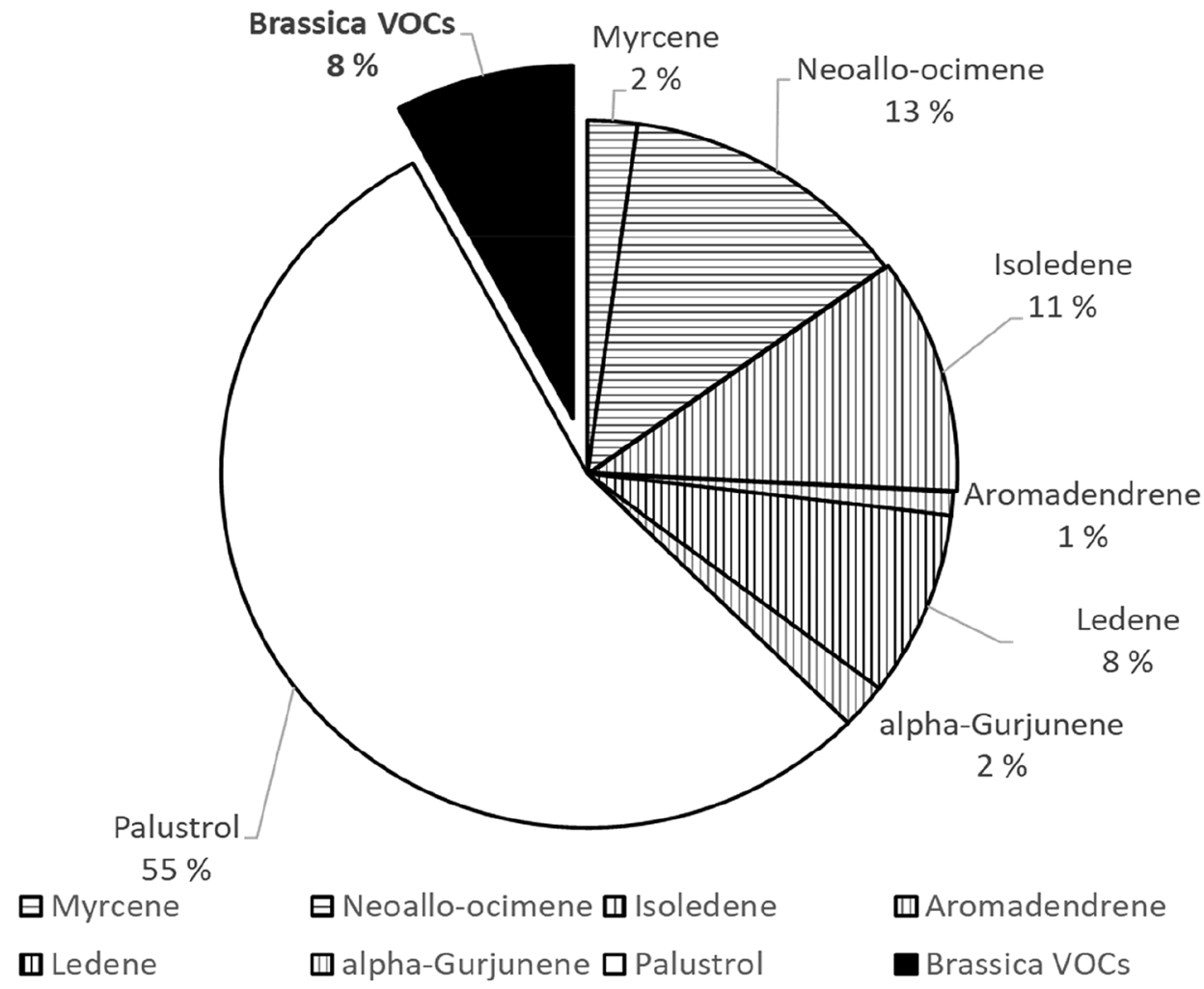

\section{Parasitoids for experiments}

Cocoons of parasitoid C. glomerata which were originally received from Wageningen University (Khaling et al. 2016) were reared on larvae of $P$. brassicae on broccoli (B. olera$c e a)$ plants in insect cages in an insect rearing room (conditions: temperature $23^{\circ} \pm 2{ }^{\circ} \mathrm{C}, \sim 60 \% \mathrm{RH}, \mathrm{L} 16 \mathrm{~h}$ : D $8 \mathrm{~h}$ photoperiod, light intensity of $300 \mu \mathrm{mol} \mathrm{m} \mathrm{m}^{-2} \mathrm{~s}^{-1}$ ). Adult wasps were fed with $25 \%$ honey solution and tap water soaked in cotton wool. To synchronise the emergence of parasitoid $C$. glomerata, $P$. brassicae larvae were parasitized on the same day to be collected, and then the parasitized P. brassicae larvae by the wasps were kept on Brussels sprouts plants in cages. After that, the eggs of wasps were collected on the same day and maintained in the same cages to have adults of $C$. glomerata on the same day for these experiments. In addition, $C$. glomerata was reared on $P$. brassicae larvae grown on non-RT-exposed plants.

\section{Exposure of $B$. oleracea to $R$. tomentosum volatiles}

For RT exposure, the set-up was identical as used with $B$. oleracea plants in an earlier $P$. xylostella behavioural and volatile analysis study on $R$. tomentosum (Himanen et al. 2015). Here, the corresponding $B$. oleracea var. italica control plants with no RT exposure, as well as the equal plants used for RT-exposure were enclosed inside insect cages in fume hoods of laboratory for about $8 \mathrm{~h}$ at $22{ }^{\circ} \mathrm{C}$ of the previous day, followed by $16 \mathrm{~h}$ at $6{ }^{\circ} \mathrm{C}$ (in the cold room temperature, representing typical early summer nighttime minimum temperature) until the start of the oviposition, host choice and orientation behaviour of C. glomerata experiments (Fig. 2). Bases of 15 cut RT branches with $25-30 \mathrm{~cm}$ high (collected from the natural habitat right before the experiments) that had their stems in waterfilled 250-ml decanter bottles were confined in insect cages $(33 \times 33 \times 60 \mathrm{~cm}$, with two sides of the cages covered with a fabric mesh) together with four pots of 21-days-old B. oleracea plants (with four plants per pot). The cages for control also had a similar set-up but without RT branches.

Exposure started at 10:00 a.m. at room temperature $\left(+22{ }^{\circ} \mathrm{C}\right)$ in a fume hood, where air flow was from the bouquet of branch towards $B$. oleracea seedlings with the minimum distance of $10 \mathrm{~cm}$ between emitters plant and receiver plants. At 6 p.m. the cages were transferred to cold room at temperature of $6{ }^{\circ} \mathrm{C}$ until following morning when biotests at $6{ }^{\circ} \mathrm{C}$ or at $22{ }^{\circ} \mathrm{C}$ with $P$. brassicae larvae or adults were established. The colder temperature at night was used to mimic cold boreal early summer night temperatures. After $24 \mathrm{~h}$, the plants were transferred into insect experiments at $6{ }^{\circ} \mathrm{C}$ and $22{ }^{\circ} \mathrm{C}$, respectively.

\section{Oviposition by $P$. brassicae females}

The 6-h long oviposition choice experiments of P. brassicae adults with RT-exposed and control $B$. oleracea plants 

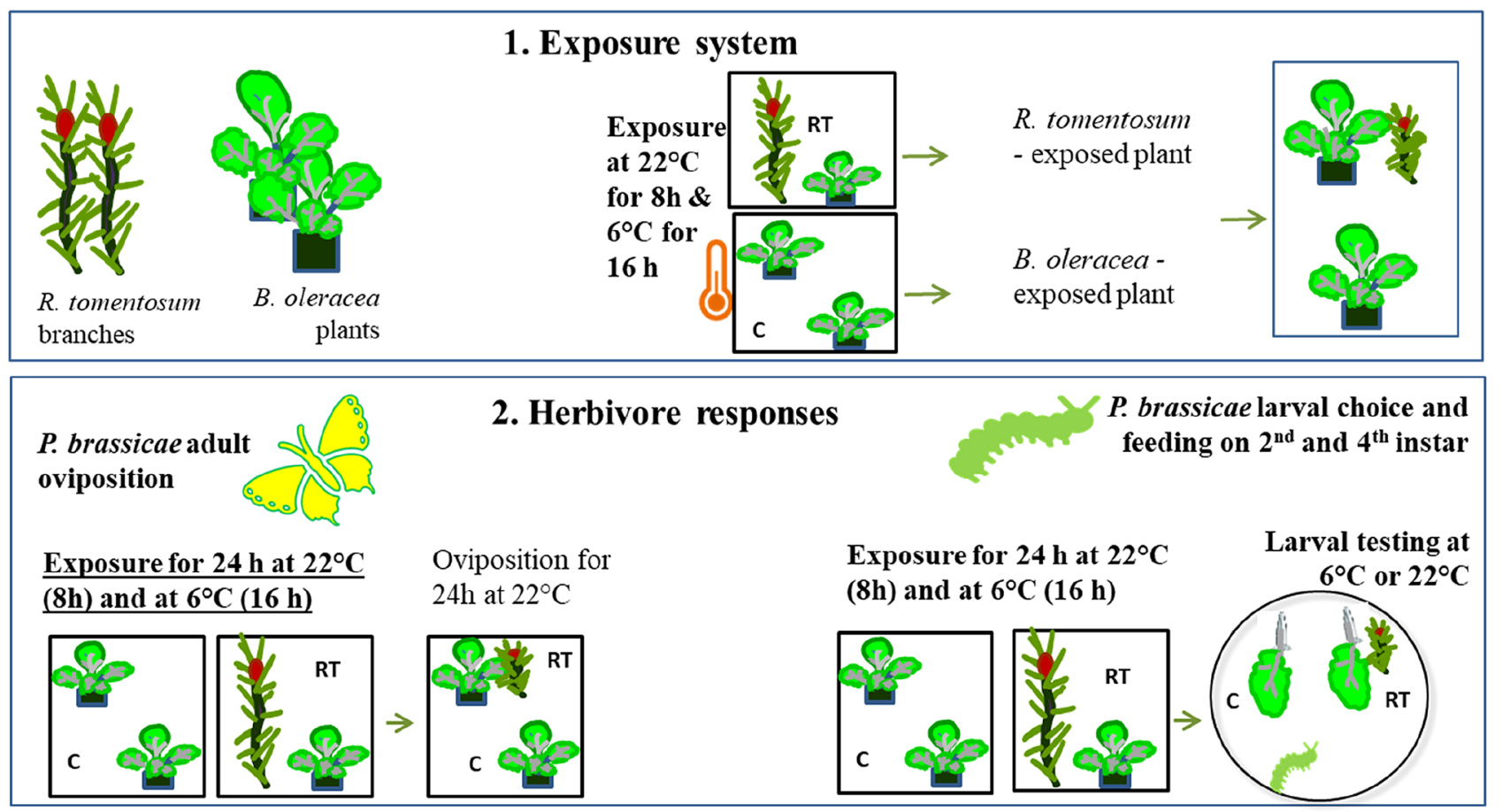

Exposure for $24 \mathrm{~h}$ at $22^{\circ} \mathrm{C}$ $(8 \mathrm{~h})$ and at $6^{\circ} \mathrm{C}(16 \mathrm{~h})$

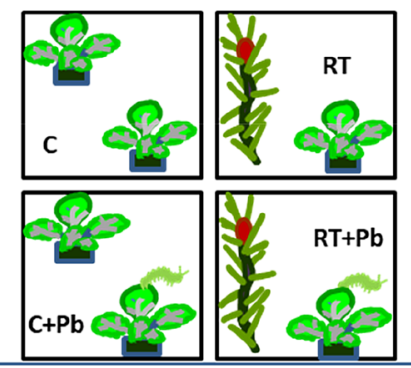

3. Parasitoid Cotesia glomerata attraction test

Combinations tested at $22^{\circ} \mathrm{C}$
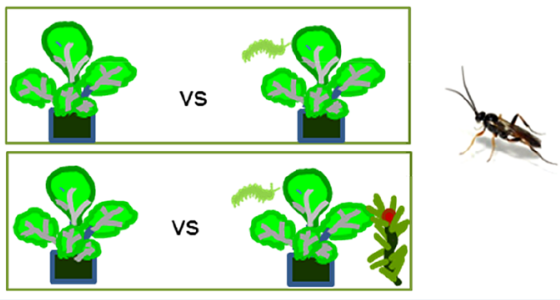

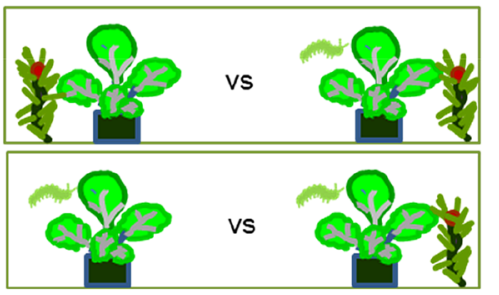

Fig. 2 Schematic presentation of the experimental set ups. There were three parts of testing plant $B$. oleracea, herbivore $P$. brassicae and parasitoid $C$. glomerata responses towards RT- exposure. The used temperatures varied in each part regarding the response to be tested and represented the variations of boreal environmental temperatures between early summer night-time and day-time temperatures. In Part 1, Exposure system (background of our research team), to reveal whether a temperature-dependent adsorption-desorption process of RT semivolatiles occurs on $B$. oleracea, the night-time minimum temperature was a $6{ }^{\circ} \mathrm{C}$ versus daytime was used of $22{ }^{\circ} \mathrm{C}$. In
Part 2, exposure of B. oleracea to RT was conducted and the $P$. brassicae ovipositions were compared at $22{ }^{\circ} \mathrm{C}$ (average day-time temperatures). Larval choice and feeding were tested at stabile $6{ }^{\circ} \mathrm{C}$ and $22{ }^{\circ} \mathrm{C}$ temperatures to allow comparison for the feeding between the night-time versus day-time temperatures along with the RT exposures of representative temperature. In Part 3, female $C$. glomerata parasitoids (day-active) were tested for olfactory orientation. The prior conducted RT exposure were tested at $22{ }^{\circ} \mathrm{C}$ because of the average daytime temperature $\left(2{ }^{\circ} \mathrm{C}\right) . \mathrm{Pb}=P$. brassicae. Photos of parasitoid: Professor Jarmo Holopainen were conducted in an insect rearing room at temperature of $22{ }^{\circ} \mathrm{C}$. Each experiment took place under approximately 250-300 $\mu \mathrm{mol} \mathrm{m}^{-1} \mathrm{~s}^{-1}$ PAR from 9:00 a.m. until 03:00 p.m. Two similar oviposition experiments with 11 replicate cages were conducted and analyzed separately, because the butterflies used in these experiments originated from the different generations of the insect rearing. Four females and four males of 1-2 days old P. brassicae butterflies were randomly selected from the mixed-gender stock population and released into each cage. A vial with mix of honey and water was available for feeding of the butterflies. After a 6-h oviposition period, the B. oleracea plants were removed from cages and stored at $+6{ }^{\circ} \mathrm{C}$ until egg counting. After egg and egg cluster counting, the number of eggs and egg clusters per each pot (on all four plants) were calculated and used for the statistical analyses. 


\section{Host choice and feeding by $P$. brassicae larvae}

At two temperatures, either at the cold room $+6{ }^{\circ} \mathrm{C}$ or at laboratory $+22{ }^{\circ} \mathrm{C}$, two independent experiments with 48 replicate petri dishes (two similar tests with 24 dishes) were conducted on $P$. brassicae larvae (both 2 nd and 4th instars). For herbivore choice experiment, one leaf of RT-exposed and one leaf of control B. oleracea var. italica plant was enclosed in each petri dish (a diameter of $13 \mathrm{~cm}$ ) with their petioles in water- filled $1.5 \mathrm{ml}$ Eppendorf tubes and set on a filter paper placed on the bottom of the dish. An equal light intensity (approximately $300 \mu \mathrm{mol} \mathrm{m} \mathrm{m}^{-1} \mathrm{~s}^{-1}$ ) was created in all experiments by placing similar fluorescent lamps above the dishes.

Brassica oleracea leaves for the experiments were collected from plants at $+6{ }^{\circ} \mathrm{C}$ after their $24 \mathrm{~h}$ exposure to RT or B. oleracea plants (control treatment). Both leaves taken in one petri dish were approximately of the same size to eliminate size effect on larval preference test. Leaves of control and RT-exposed plants were handled with separate forceps to avoid any contamination of RT volatiles on control plant leaves. To test whether adhered VOCs could be stronger repellent in younger than older instar larvae (Rossiter et al. 1986), we selected second- and fourth instar $P$. brassicae larvae to represent younger and older instar larvae, respectively. We determined by head capsule slippage 1 st and 3rd instar P. brassicae larvae beginning to moult and those were chosen for experiments. One newly molted second-instar (about $12 \mathrm{~mm}$ ) or four-instar (around $32 \mathrm{~mm}$ ) larva of $P$. brassicae was released between control leaf and RT-exposed leaf in the middle of each Petri dish. The glass lids of Petri disks were covered and sealed around the Petri dishes by sealing film (Parafilm ${ }^{\circledR}$, Bemis Company, Inc, Neenah, WI, USA). Thus, the possibly released semi-volatile compounds from leaves could not leak outside.

In each of the $24 \mathrm{~h}$ larval choice behaviour test, larval position in the dish was monitored at 10 min intervals during the first $2 \mathrm{~h}$ of the test and after this, at $1 \mathrm{~h}$ or longer intervals. During the monitoring, the position of the larvae in each dish was recorded to indicate if they were on control leaf, on RT-exposed leaf or outside the leaves indicating "no selection". In total, the trial lasted approximately $24 \mathrm{~h}$. The consumed leaf was not measured because of variable size of leaves between dishes, which each dish had equal sized leaves to be selected by one larva.

\section{Orientation behaviour of C. glomerata}

Olfactory orientation of the parasitoid C. glomerata was studied by using Y-tube olfactometer with four different comparisons (plant pairs) from respective broccoli plants originating from laboratorial treatments at $+22{ }^{\circ} \mathrm{C}$. The comparisons were: (1) intact plant versus host-damaged plant (to verify the functioning of the system for testing orientation of the parasitoid to host damage); (2) intact plant versus host-damaged RT-exposed plant (to determine whether RT exposure disturbs the olfaction of induced volatiles); (3) host-damaged plant versus host-damaged RT-exposed plant (to determine whether $C$. glomerata is able to discriminate between these); and (4) RT-exposed plant versus host-damaged RT-exposed plant (to determine whether $C$. glomerata is intrinsically affected by neighbouring RT VOC exposure, and whether this disrupts host finding). Experimental set-ups of the study are described in Fig. 2.

We used both 2 nd and 4th instar larvae to feed on plants to create sufficient fresh damage of diverse-aged larval population, but at same time to avoid total destruction of the seedlings. Control tests without exposing B. oleracea plants to RT volatiles were first conducted. For host-damage treatments, the larvae which had moulted to the 2 nd and 4th instar, were starved for $2 \mathrm{~h}$ and $4 \mathrm{~h}$ respectively. Total of 16 both newly moulted 2 nd and 4 th instar larvae were placed on each damage-treatment $B$. oleracea plant pot (It means that each two of 2 nd and 4 th instar $P$. brassicae larvae were released on each $B$. oleracea plant. However, there were four $B$. oleracea plants per pot, accounted for 8 of 2 nd instar and 8 of 4th instar larvae) to feed for $45 \mathrm{~min}$ in laboratory conditions at $+22{ }^{\circ} \mathrm{C}$. The larvae were removed from the experimental plants before using the plants in olfactometer tests.

For host-damaged RT-exposed B. oleracea plant treatments, RT-exposed $B$. oleracea plants were kept in a temperature-controlled room (at $6{ }^{\circ} \mathrm{C}$ ) before the tests were used. To ensure equal damage level along with adhesion and persistence of the exposure-originating VOCs in the test laboratory conditions $\left(\mathrm{at}+22^{\circ} \mathrm{C}\right.$ ), the larval feeding process to RT-exposed plants was performed for $45 \mathrm{~min}$ in the laboratory at $+22{ }^{\circ} \mathrm{C}$. This took place right after those plants were taken from a cold room conditions and the newly molted 2 nd and 4th instar larvae were starved for 2 and $4 \mathrm{~h}$, respectively. After this, the larvae were removed and host-damaged RTexposed $B$. olerace a plant pots were immediately transferred to the laboratory, where olfactometry tests were conducted (as previously described for the host-damage treatment).

Y-tube olfactometer (diameter $=1.6 \mathrm{~cm}$, main arm $=10.5 \mathrm{~cm}$, other arms $10 \mathrm{~cm}$, and angle between them $90^{\circ}$ ) (Egigu et al. 2010; Pinto et al. 2007) was used to assess the orientation of the parasitoid $C$. glomerata. All the glass wares were sterilized at $121^{\circ}$ before use. Moreover, after each tested insect, the Y-tube olfactometer was turned horizontally around, and after every third-tested insect it was rinsed with $96 \%$ ethanol.

Test plants in the pot covered with aluminum foil were enclosed inside 22-1 glass vessel and both vessels were connected with Teflon tubes into the two arms of Y-tube to assess the orientation of parasitoids (Himanen et al. 2009, 2015). There was an equal and constant flow of 
charcoal-filtered and ozone-scrubbed pressurized air in glass vessel, which was adjusted with pressure and needle valves.

The olfactometers was operated at an air-flow rate $(500 \mathrm{ml})$, which was measured every time when plant or jar was changed. It was calibrated with M-5 mini-Buck calibrator between the olfactometer and those two glass vessels. The experiment was conducted in a laboratory with a constant temperature condition at $22{ }^{\circ} \mathrm{C}$. An equal light level (approximately $300 \mu \mathrm{mol} \mathrm{m} \mathrm{m}^{-1} \mathrm{~s}^{-1}$ ) was provided by with Osram Delux F, 24 W fluorescent lamps (Osram AG, Munich, Germany) by placing one lamp above each vessel and above the olfactometer.

Prior to the olfactory orientation testing, 2- to 4-days-old gravid females of $C$. glomerata wasps were chosen for the Y-tube olfactometer assays. For each trial for testing the orientation behaviour of the female parasitoids, one individual wasp was carefully introduced manually into downwind at the opening of a Y-tube. Each individual female wasp was used only once for the experiments and the behaviour was observed no longer than $5 \mathrm{~min}$, or until they made their final choice earlier. A "choice" of parasitoid wasp in orientation behaviour testing was decided, when it walked about twothirds along an arm of the olfactometer and remained there for at least $3 \mathrm{~s}$. The results were recorded as the choices of the parasitoids which seemed clearly in the pair of the experimented odours. In each experiment, 102-116 wasps were tested for each comparison.

\section{Statistical analyses}

All tests were performed with IBM SPSS statistics 25.0 for Windows (IBM Corp., Armonk, NY, USA). All data were checked for normality and equality of variances before statistical analysis and log-transformed to meet the requirements when needed. For larval choice experiment, Chi square tests were used to test the selection frequency of larvae. In the oviposition experiment data of $P$. brassicae females, the eggnumbers per pot (four plants) were analysed by using the paired Student's $t$-test for the main effects of experimental treatment, temperature and their interaction, including the experiment as a random effect, using a mixed model for logtransformed values. The number of egg-clusters per pot were analysed using a non-parametric Wilcoxon Signed Ranks Test for two related samples. The binomial test was used to analyse the data from the orientation response assay of the parasitoid C. glomerata.

\section{Results}

\section{Oviposition experiments}

In the 1st experiment, $P$. brassicae females deposited marginally significantly lower numbers of eggs per pot (four plants) on RT-exposed B. oleracea plants than on control $B$. oleracea plants, but there was only a marginal statistical difference $\left(t_{10}=2.223, P=0.05\right.$, the paired Student's $t$-test $)$ (Fig. 3a). Furthermore, the number of egg cluster per pot on RT-exposed B. oleracea plants were significantly lower $(Z=-2.316, P=0.021$, Wilcoxon Signed Ranks Test) than on control plants. (Fig. 3b).

In exp. 2, the number of laid eggs by $P$. brassicae females on plants in RT-exposed pots were significantly lower $\left(t_{10}=2.467, P=0.033\right)$ than on control plants
Fig. 3 The oviposition by P. brassica females and the number of egg-clusters per pot on control and $R$. tomentosum (RT)-exposed B. oleracea plants in two experiments: a-d. “*” letters above charts indicate significant differences at $P<0.05$ by Wilcoxon Signed Ranks Test
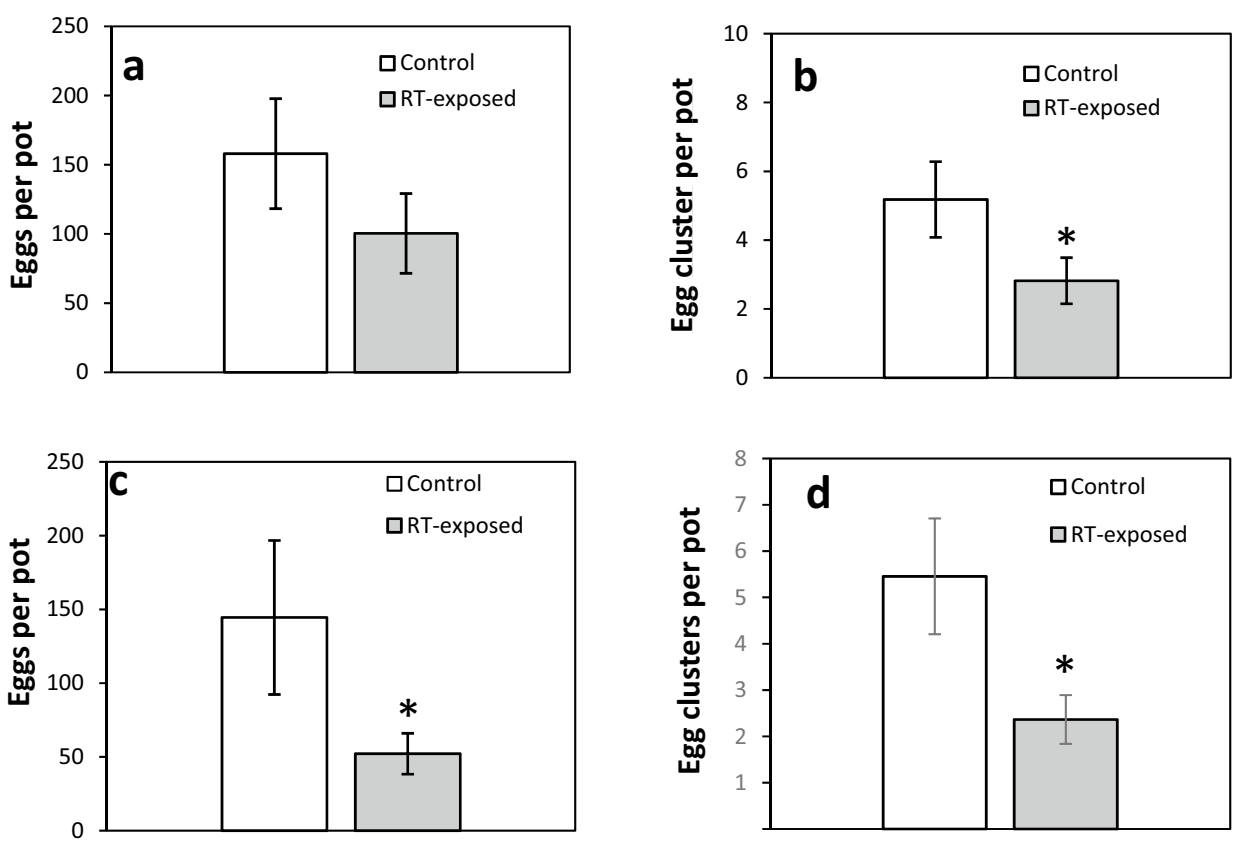
(Fig. 3c). Also, the number of egg clusters on RT-exposed plants were significantly lower $(Z=-2.144, P=0.032)$ than on control (Fig. 3d).

\section{Larval choice and feeding preference experiments}

Both the 2nd and 4th instar P. brassicae larvae at both tested temperatures showed significant and highly significant $\left(2\right.$ nd instar at $6{ }^{\circ} \mathrm{C}(P=0.041)$ and $22{ }^{\circ} \mathrm{C}(P<0.001)$, 4 th instar at $6{ }^{\circ} \mathrm{C}(P<0.001)$ and $22{ }^{\circ} \mathrm{C}(P=0.008)$, Chisquare test) avoidance of RT-exposed leaves over the first test hours (tested timeframe varying from 1 to $10 \mathrm{~h}$ ). However, except at one observation point (at $40 \mathrm{~min}$ ), there were no significant differences in the 2 nd instar $P$. brassicae larval choice behaviour between the control and the RT-exposed leaves (with $P=0.102$ ). Additionally, the cold temperature inhibited the development rate of the 2 nd and 4th instar $P$. brassicae compared to the warmer temperature at $22{ }^{\circ} \mathrm{C}$. The larval choice activity at $6{ }^{\circ} \mathrm{C}$ (Fig. 4a, b) was slower than at $22^{\circ} \mathrm{C}$ (Fig. 5a, b), and therefore the test was continued for a longer time at the colder than the higher temperature.

In the 2nd experiment (Fig. 5), the 4th instar P. brassicae larvae preferred control to RT-exposed $B$. oleracea leaves, with a statistically significant difference $(P<0.05$; $P<0.01 ; P<0.001$. No asterisk as "-" was used in some cases where ratios are 100:0, Chi-square test). Statistical significance is given in Fig. 5a and b at both temperatures. Overall, RT-exposed B. oleracea leaves received less larval choices than equal distribution at $50 \%$, compared with control leaves.

\section{Orientation behaviour of parasitoid C. glomerata}

The choosing rates of parasitoid $C$. glomerata, which highly significantly preferred volatiles from $P$. brassicae-damaged B. oleracea plants over intact plants as an odour source, were $>60 \%$ in all four orientation assays (Fig. 6).

RT-exposure of both control and P. brassicae-damaged plants did not disturb $C$. glomerata orientation towards damaged plant (test 3 ). However, the $P$. brassicae-damaged RT-exposed plants were highly significantly less preferred compared to the non-RT-exposed damaged plants (test 4).

\section{Discussion}

Our results showed that exposure of broccoli plants to $R$. tomentosum VOCs reduced the oviposition and larval preference of the major herbivore pest $P$. brassicae under laboratory conditions. We did not find clear reduced larval avoidance of leaf disk with adhered RT terpenoids in larger 4th instars larvae when compared to younger 2 nd instar larvae as we expected on the basis of results of Rossiter et al. (1998). Against the hypothesis, in the beginning of the experiment at $+6{ }^{\circ} \mathrm{C}$, small 2 nd instar larvae did not show preference to untreated control leaf disks. These observations are in agreement with earlier results indicating EACC and associational resistance by another Brassicaceae herbivore $P$. xylostella after host plant exposure to $R$. tomentosum volatiles (Himanen et al. 2015; Mofikoya et al. 2018a). However, the parasitoid C. glomerata preferred non-RT-exposed $P$. brassicae damaged plants compared to RT-exposed $P$. brassicae damaged plants. This

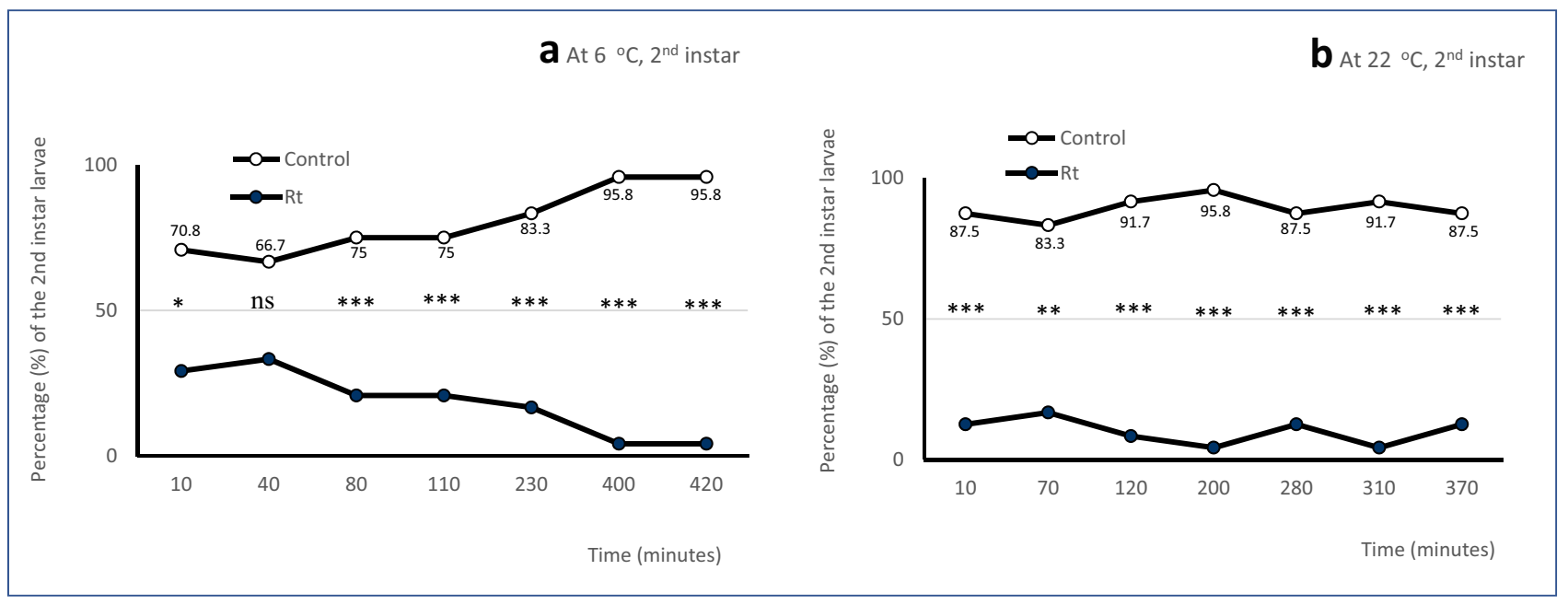

Fig. 4 The 2nd instar larval choice percentages of $P$. brassicae towards Control and $R$. tomentosum (RT)-exposed B. oleracea leaves. The choice tests were performed on 48 replicate Petri dishes. Statistically significant larval choice in the selection frequency of larvae were indicated by asterisks ( $n s$ not significant difference; “*” letters above charts indicate significant differences at $P<0.05$; “**" at $P<0.01$; “***" at $P<0.001$ by $\mathrm{Chi}$ square test). The exposure and test temperature were in a) $+6{ }^{\circ} \mathrm{C}$, and in b) $+22^{\circ} \mathrm{C}$ 


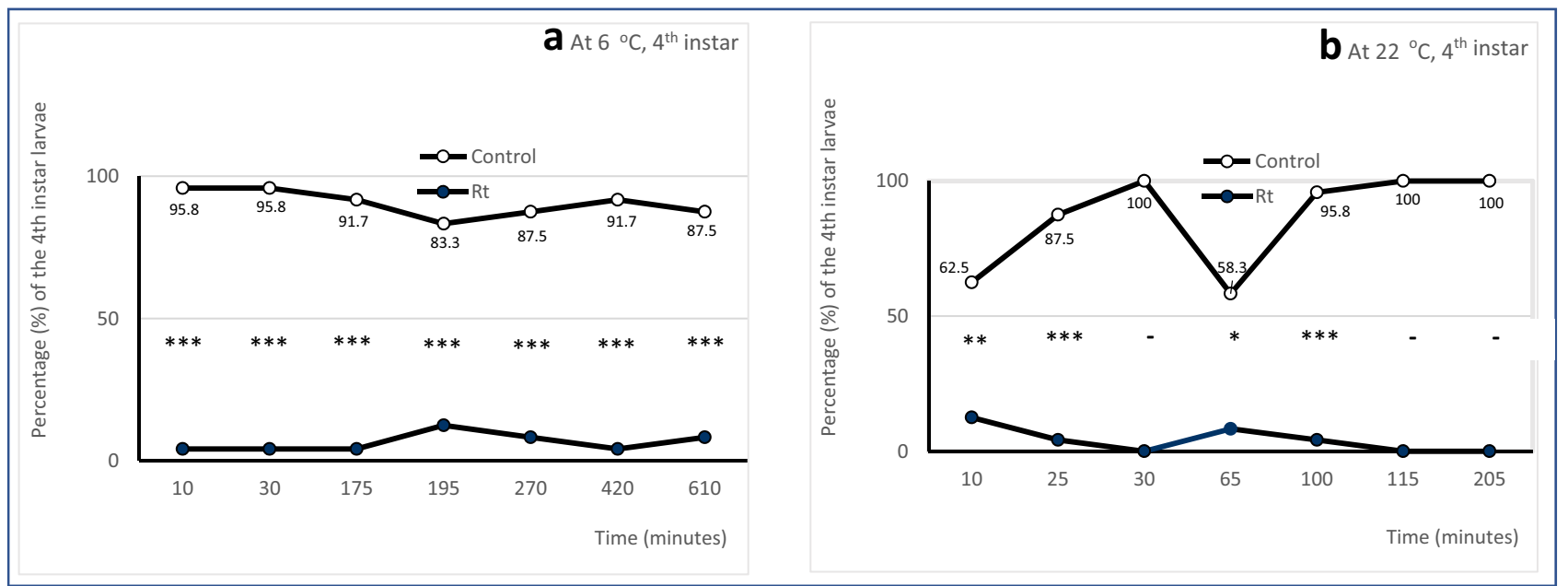

Fig. 5 The 4th instar larval choice percentages of $P$. brassicae towards Control and $R$. tomentosum (RT)-exposed B. oleracea leaves. The choice tests were performed on 48 replicate Petri dishes. Statistically significant larval choice in the selection frequency of larvae are indicated by asterisks ( $n s$ not significant difference; “*” letters above charts indicate significant differences at $P<0.05$; “**" at $P<0.01$; “***" at $P<0.001$. No asterisk as "-_" are used in some cases where ratios are 100:0, indicating extreme deviation from the expected 50:50 ratio, in Chi square test). The exposure and test temperature were in $\mathbf{a}+6{ }^{\circ} \mathrm{C}$, and in $\mathbf{b}+22{ }^{\circ} \mathrm{C}$

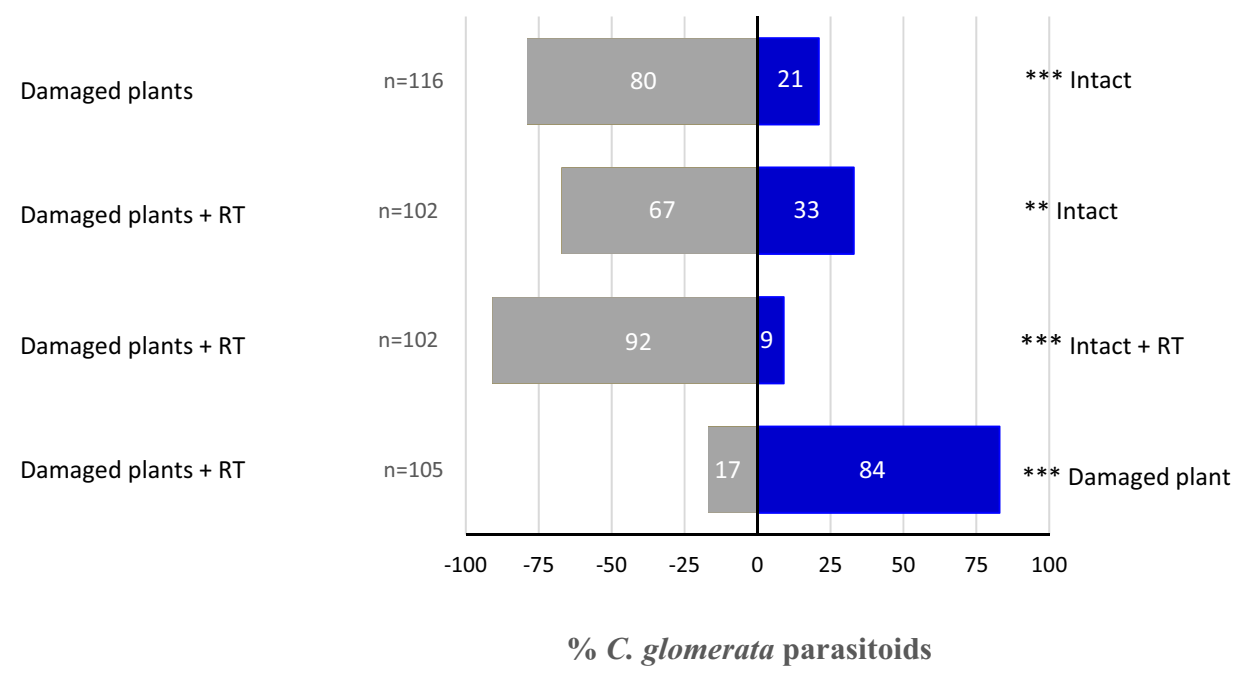

Fig. 6 Orientation of the parasitoid Cotesia glomerata in at $22{ }^{\circ} \mathrm{C}$ temperature Y-tube olfactometer behavioural assays. The selection of the individually tested parasitoids, regarding both the percentage $(\%)$, total number $(n)$ of tested parasitoids and number of individuals making a selection towards either of the odour sources in a two-arm olfactometer are reported. Female parasitoids were tested on intact, host-damaged and $R$. tomentosum (RT)-exposed $B$. oleracea plants. Host-damaged plants were subject to $P$. brassicae larval feeding for $45 \mathrm{~min}$, whereas RT-exposed plants neighboured $R$. tomentosum branches for $24 \mathrm{~h}$ before testing. Statistically significant preferences in the selections are indicated by asterisks (“**") at $P<0.01$ and “***" at $P<0.001$, in binomial test) was the main difference when compared to behaviour of Cotesia vestalis parasitoid, which did not respond to RT-exposure when RT-exposed and non-exposed hostdamaged ( $P$. xylostella feeding) plants were compared (Himanen et al. 2015). We did not have a possibility to analyse RT-emitted VOCs adsorbed by B. olearacea foliage in this experiment, but similar exposure systems have consistently led to notable RT fingerprints in receiver plant emissions (Himanen et al. 2010, 2015; Mofikoya et al. 2018a). The repellent or camouflaging effects of RT exposure detected in our larval preference and oviposition experiments suggest that the major RT sesquiterpene alcohol palustrol and possibly some other RT-volatiles were successfully adsorbed on B. oleracea plants in the used exposure set-up. 


\section{Oviposition disturbed by RT exposure of host plant}

Oviposition rates by $P$. brassicae females were significantly decreased in one experiment and only marginally significantly decreased in another experiment on RT-exposed $B$. oleracea plants. This suggests that $R$. tomentosum volatiles could regulate pest population pressure on broccoli by affecting egg deposition, but under high oviposition pressure with several females the repellent effect might not be significant. Gravid P. brassicae females are sensitive for the chemical quality and VOCs emitted by their host plant. Females can avoid landing on Brassica plants that already emit oviposition-induced volatiles indicating future herbivore pressure by larvae of another $P$. brassicae female, interspecific larval competition, and food shortage (Fatouros et al. 2012). However, $P$. brassicae females did not avoid landing on plants having eggs laid by the generalist herbivore species, cabbage moth Mamestra brassicae (Fatouros et al. 2012). Similarly, related Pieris rapae L. avoided laying eggs on plants damaged by conspecific larvae but did not avoid $P$. xylostella damaged plants (Shiojiri et al. 2015). Our both oviposition experiments indicated reduced egg-cluster number and reduced total egg number on plants exposed to RTvolatiles during the $6 \mathrm{~h}$ oviposition period, suggesting that $P$. brassicae females avoid laying eggs on plants that release volatiles atypical for undamaged Brassica volatile bouquet. However, we did not monitor, if occupation of control seedlings already by $P$. brassicae eggs led to further oviposition efforts preferably on RT-exposed plants. This should be tested in future more extensive behavioural tests with individually introduced female butterflies.

Gravid $P$. xylostella moths have also laid lower number of eggs on broccoli plants exposed to RT-volatiles than on plants exposed to undamaged broccoli plants (Himanen et al. 2015). Furthermore, Girón-Calva et al. (2016) showed that both $P$. brassicae and P. xylostella lay a lower number of eggs on cabbage plants exposed to volatiles of damaged conspecific neighbours than on plants exposed to undamaged conspecific neighbours under field conditions. It was suggested that VOCs from damaged neighbouring plants are passively adsorbed by undamaged plant leaves, altering the foliage quality less suitable for ovipositing females (Girón-Calva et al. 2016). It can be speculated that some of the adsorbed RT volatiles on Brassica plant may disturb the natural VOC composition (Conchou et al. 2019) of the host plant of $P$. brassicae so much that it will not anymore meet the sensory requirements for a suitable host (Conchou et al. 2019). Other possibility could be that some of the adsorbed RT VOCs may suppress the sensing of some key VOCs (Hatano et al. 2015) of the host plant by $P$. brassicae.
Pieris brassicae larvae avoid settling on RT-exposed leaves

Our results revealed that younger 2nd and older 4th instar $P$. brassicae larvae consistently avoided RT exposed leaves at both simulated night $\left(+6^{\circ} \mathrm{C}\right)$ and daytime $\left(+22^{\circ} \mathrm{C}\right)$ temperatures. This suggests that despite the different temperatures, the semi-volatile compound had been emitted by RT plants and absorbed by the broccoli leaves. An earlier study, with the diamond back moth P. xylostella (Himanen et al. 2015) with a similar laboratory exposure system showed that $P$. xylostella preferred control broccoli leaves over RT-exposed leaves at $+12{ }^{\circ} \mathrm{C}$ but did not avoid RT-exposed leaves in daytime temperature $\left(+22{ }^{\circ} \mathrm{C}\right)$. In our study P. brassicae avoided RT-exposed leaves at $+22^{\circ} \mathrm{C}$. This possibly indicates a higher VOC emission rate of RT-branches and consequent higher adsorption rate and longer persistence of RT volatiles on the $B$. oleracea leaves than in study by Himanen et al. (2015). The intraspecific variation of plant VOC composition (Aartsma et al. 2019; Egigu et al. 2010; Himanen et al. 2015; Jankowska 2010; Khaling et al. 2015) such lack of sesquiterpene ledol and high proportion palustrol in RT provenance used in this study (Mofikoya et al. 2018a) could be another reason for variable response of $P$. xylostella and $P$. brassicae responses at $+22{ }^{\circ} \mathrm{C}$, but this needs further studies with parallel VOC measurement during behaviour tests.

At cold temperatures $\left(+6{ }^{\circ} \mathrm{C}\right)$, the pest larvae (being Ectotherms) often have less movement, because the cold temperature can cause major disruptions in the central metabolism of cells, leading to the lower and slower metabolic rates and higher energy costs (Denlinger et al. 2010). Indeed, the movement of $P$. brassicae larvae at $+6{ }^{\circ} \mathrm{C}$ was much slower and the larvae spent much more time for making their choice than at $+22{ }^{\circ} \mathrm{C}$. Our results suggest also that, for example, the smaller 2nd instar larvae were more strongly affected by the colder $\left(+6{ }^{\circ} \mathrm{C}\right)$ temperature than the 4th instar larvae, because considerable proportion of the 2nd instar larvae had not selected host plant leaf within the first $230 \mathrm{~min}$. This suggests that the cold temperature could inhibit some individuals of $P$. brassicae larvae, but we may conclude again that it had not become a decisive element, since there were no significantly different results gained from the experiments at $+6{ }^{\circ} \mathrm{C}$ compared to the warmer temperature at $+22{ }^{\circ} \mathrm{C}$. P. brassicae larvae development and activity is strongly dependent on temperature. $P$. brassicae larval period last about 12 days at temperatures above $27.5^{\circ} \mathrm{C}$ (Bisht et al. 2001; Das 2018) and could be 19 days or longer at $15{ }^{\circ} \mathrm{C}$ (Bisht et al. 2001; Das 2018). Therefore, it can be assumed that the carried experiments in the cold temperature condition $\left(\mathrm{at}+6^{\circ} \mathrm{C}\right)$ had severely inhibited their host-choice and feeding activity of the 2 nd and 4 th instar $P$. brassicae. 
Overall, the larval behaviour in both temperatures showed rather consistent avoidance of RT-exposed leaves, even if there is a possibility that RT volatiles adsorbed on leaf surface might have been released from RT-exposed leaves into the petri dish air space at $+22{ }^{\circ} \mathrm{C}$ temperature. Previous studies with RT volatiles (Himanen et al. 2010, 2015; Mofikoya et al. 2018a, b) have not assessed how much emitter plant volatiles adhered on other plant foliage is adsorbed on leaf surface wax layer (Li and Blande 2015) and how much is taken up by stomata (Niinemets et al. 2014). It could be possible that substantial amount of RT volatiles during exposure has been taken up by actively growing Brassica leaves though stomata and stored in leaf mesophyll lipids (Noe et al. 2007). Therefore, more detailed studies of uptake and surface adsorbing mechanisms of neighbouring plant VOCs are needed to better understand the importance of bidirectional exchange of biogenic volatiles (Niinemets et al. 2014) for plant-herbivore and herbivore-parasitoid interactions.

We did not analyse volatile or semi-volatile compounds in this study. Following the exposure protocol used with RT exposure in an earlier study (Himanen et al. 2015), which showed adsorption of RT volatiles on B. oleraceae leaves, we assume that the RT volatiles were adhered on leaves of exposed plants and were most or at least partly responsible for the detected repellent effects on P. brassicae larvae. In natural field conditions, Betula spp. foliage was capable to adsorb RT VOCs when $R$. tomentosum was growing as a neighbouring plant and Betula seedlings showed some, while not universal, reduction in selected herbivore pressure tested on leaf weevils and aphids (Himanen et al. 2010).

\section{Parasitoid wasps prefer damaged host plants over intact plants, even when exposed to $R$. tomentosum VOCs}

RT-exposure did not prevent the Hymenopteran parasitoid C. glomerata to orientate towards $P$. brassicae-damaged plants when compared to intact RT exposed plants. However, among $P$. brassicae-damaged plants, this parasitoid preferred damaged plants which were not pre-exposed to RT-volatiles. Earlier study with a specialist larval parasitoid $C$. vestalis of P. xylostella, Himanen et al. (2015) found that $C$. vestalis preferred host-damaged plants despite of RT exposure of host plant, but among host-damaged plants RTexposure did not affect parasitoid preference. In that sense, our results with $C$. glomerata were different and RT-exposure reduced parasitoid orientation to damaged host plants. In field scale, this could mean that a crop plant having higher concentration of adhered RT-volatiles may have lower parasitoid pressure on $P$. brassicae larvae and might face more larval damage. On the other hand, this will be compensated with lower oviposition pressure of RT-volatile-rich Brassica plant by $P$. brassicae.

Lack of response of parasitoids such as $C$. vestalis to exogenous non-host plant VOCs in host plant volatile bouquet (Himanen et al. 2015) can be a result of their high sensitivity to typical herbivore-induced VOCs from plants damaged by their host larvae and the specific key compounds in their composition (Khaling et al. 2016; Ponzio et al. 2014). C. glomerata preference to RT-exposed and host-damaged broccoli plant when compared to intact plant indicates that RT-volatiles do not block sensing of herbivore-induced Brassicaceae volatiles in this parasitoid wasp species, but the wasp reduces its preference if a similar bouquet is available without RT volatiles. The differences in $C$. glomerata and $C$. vestalis may indicate that the response to non-typical host plant volatiles could be species specific. Earlier behavioural tests with Cotesia rubecula wasps gave evidence that these wasps are not affected by transgenic isoprene-emitting Arabidopsis plants damaged by the host moth species. However, another parasitoid wasp species Diadegma sp. was repelled by these transgenic Brassicaceae plants emitting isoprene and the wasps preferred wild type plants (Loivamaki et al. 2008).

\section{Potential of neighbouring plant VOCs to protect from herbivores}

Companion cropping, for example by planting aromatic companion plants next to crop plants susceptible to major pest insects, is an old method for pest control in traditional and organic farming (Beizhou et al. 2012; Jankowska 2010; Ninkovic et al. 2013; Parolin et al. 2012; Sukegawa and Arimura 2019). The improved resistance of the main crop against herbivores is explained e.g., by neighbour-induced priming and production of chemical defence compounds in healthy crop plants (Sukegawa and Arimura 2019). These compounds act as typical herbivore-induced VOCs in crop plants, which prime plants to be better prepared against herbivore pressure (and competing plant) (Ninkovic et al. 2013). Exposure of Brassica rapa L. plants to volatiles of intact peppermint Mentha $\times$ piperita $\mathrm{L}$. plants by growing them within 10-100 $\mathrm{cm}$ distances from peppermint plants, activated transcript accumulation levels of both JA- and SAsignalling-dependent defence genes in B. rapa and reduced feeding damage by the Lepidopterous larvae including Pieris rapae and P. xylostella (Sukekawa and Nakamoto 2018). Another experiment by Sukegawa and Arimura (2019) demonstrated that $P$. xylostella larval growth and oviposition rate were lower on Mentha-exposed B. rapa. Furthermore, production of herbivore-induced VOCs, reduced preference by stem-borer moths for egg deposition and enhanced parasitism by stem-borer parasitoid wasps in maize plants has been observed when plants were exposed to VOCs released 
by intact molasses grass (Melinis minutiflora) (Tolosa et al. 2019). These examples demonstrate that there may be yet undiscovered potential in using plant-plant interactions for designing future pest control strategies. However, profound risk assessment of potential negative allochemical effects on crop plants from aromatic natural herbs might also be needed. This will also include the assessment of the capacity of major pest insect species to learn to avoid the chemical camouflage.

In a more mechanistic sense, it is important to note that the VOCs of a companion plant or an intercropped plant are known to affect the crop plant at least by two types of activity modes, as described above. First, companion plant VOCs can be passively adsorbed on crop plant surfaces, where they stay on leaf surface wax layer ( $\mathrm{Li}$ and Blande 2015) or are taken up through stomata (Noe et al. 2007), but do not activate receiver plant's active chemical defense. The second mode is priming (Sukekawa and Nakamoto 2018) or activation of receiver plant active chemical defense by neighbouring plant volatiles leading e.g. emissions of typical herbivore-induced volatiles (Ninkovic et al. 2013; Tolosa et al. 2019). In our study, the discovered effects on $P$. brassicae behaviour by exposure of broccoli to atypical (RT) VOCs, seems to be more likely due to the first type of mechanisms, with VOCs passively adsorbed on broccoli foliage, although their existence was not measured in this particular study. However, in previous studies, no evidence of herbivore-induced VOCs such as homoterpenes or green leaf volatiles were detected in broccoli (Himanen et al. 2015) or white cabbage (Mofikoya et al. 2018a) emissions after exposure to RT branch emissions. This strongly suggests that our results are indicating EACC. For comparison, when essential oils extracted from plants are directly sprayed on the Brassicacea plants, the high concentration of terpenes might induce some cellular damage and production of typically herbivore-induced homoterpenes that attract e.g., parasitoid of moth larvae (Egigu et al. 2010).

\section{Conclusions}

Our results show that exposure of a Brassicaceae horticultural crop plant to the volatile bouquet of $R$. tomentosum will add protection against a specialist pest herbivore at the egg deposition stage and also partly at the larval developmental stage, and may thus reduce the resulting herbivore pressure at several stages of the pest attack. The exposure system we used is known to lead to adsorption and accumulation of $R$. tomentosum volatiles on receiver plants, mimicking environmentally acquired chemical camouflage. Reduced egg deposition and reduced larval preference of $P$. rapae on the sensitive receiver crop plant suggested that such mechanism relying on repellence or disguising of host VOCs by plants emitting specific semivolatiles, may be useful for suppressing agricultural insect pests. Environmentally acquired chemical camouflage shows potential as one additional tool for an integrated pest management toolbox aiming to develop more sustainable crop protection for future agriculture and horticulture needs. However, the potential multiple mechanisms operating in plant-plant interactions mediated by VOCs, their potential synergies and trade-offs, and whether companion plants with EACC properties improve receiver plant resistance in practice should be assessed rigorously in field experiments.

Acknowledgements Authors want to thank the tree anonymous reviewers for critical reading and valuable constructive comments to improve this manuscript. This study was funded by the Academy of Finland (Project 278424). First author conducted the experiments with trainees and wrote the first draft of the manuscript. All authors participated in design and data interpretation of the experiments and reviewed the manuscript.

Funding Open access funding provided by University of Eastern Finland (UEF) including Kuopio University Hospital.

Open Access This article is licensed under a Creative Commons Attribution 4.0 International License, which permits use, sharing, adaptation, distribution and reproduction in any medium or format, as long as you give appropriate credit to the original author(s) and the source, provide a link to the Creative Commons licence, and indicate if changes were made. The images or other third party material in this article are included in the article's Creative Commons licence, unless indicated otherwise in a credit line to the material. If material is not included in the article's Creative Commons licence and your intended use is not permitted by statutory regulation or exceeds the permitted use, you will need to obtain permission directly from the copyright holder. To view a copy of this licence, visit http://creativecommons.org/licenses/by/4.0/.

\section{References}

Aartsma Y, Leroy B, van der Werf W, Dicke M, Poelman EH, Bianchi FJJA (2019) Intraspecific variation in herbivore-induced plant volatiles influences the spatial range of plant-parasitoid interactions. Oikos 128:77. https://doi.org/10.1111/oik.05151

Agut B, Pastor V, Jaques JA, Flors V (2018) Can plant defence mechanisms provide new approaches for the sustainable control of the two-spotted spider mite Tetranychus urticae? Int J Mol Sci 19:614. https://doi.org/10.3390/ijms19020614

Barney J, Sparks J, Greenberg J, Whitlow T, Guenther A (2009) Biogenic volatile organic compounds from an invasive species: impacts on plant-plant interactions. Plant Ecol 203:195-205. https://doi.org/10.1007/s11258-008-9529-4

Beizhou S, Jie Z, Wiggins NL, Yuncong Y, Guangbo T, Xusheng S (2012) Intercropping with aromatic plants decreases herbivore abundance, species richness, and shifts arthropod community trophic structure. Environ Entomol 41:872-879

Benson J, Van Driesche R, Pasquale A, Elkinton J (2003) Introduced braconid parasitoids and range reduction of a native butterfly in New England. Biol Control 28:197-213 
Bisht RS, Rana DS, Mishra PN (2001) Biology of the rose aphid Macrosiphum (Sitobion) rosaeiformis Das (Homoptera: Aphididae). Ann Plant Prot Sci (India) 9:186-192

Blande JD, Holopainen JK, Li T (2010) Air pollution impedes plant-toplant communication by volatiles. Ecol Lett 13:1172-1181

Blande JD, Holopainen JK, Niinemets Ü (2014) Plant volatiles in polluted atmospheres: stress responses and signal degradation. Plant Cell Environ 37:1892-1904. https://doi.org/10.1111/pce.12352

Brodeur J, Geervliet JBF, Vet LEM (1996) The role of host species, age and defensive behaviour on ovipositional decisions in a solitary specialist and gregarious generalist parasitoid (Cotesia species). Entomol Exp Appl 81:125-132

Camacho-Coronel X, Molina-Torres J, Heil M (2020) Sequestration of exogenous volatiles by plant cuticular waxes as a mechanism of passive associational resistance: a proof of concept. Front Plant Sci 11:121. https://doi.org/10.3389/fpls.2020.00121

Conchou L, Lucas P, Meslin C, Proffit M, Staudt M, Renou M (2019) Insect odorscapes: from plant volatiles to natural olfactory scenes. Front Physiol. https://doi.org/10.3389/fphys.2019.00972

Copolovici LO, Filella I, Llusià J, Niinemets U, Peñuelas J (2005) Capacity for thermal protection of photosynthetic electron transport varies for different monoterpenes in Quercus ilex. Plant Physiol 139:485-496. https://doi.org/10.1104/pp.105.065995

Dampc A, Luczkiewicz M (2013) Rhododendron tomentosum (Ledum palustre). A review of traditional use based on current research. Fitoterapia 85:130-143

Das P (2018) Response of different temperatures on biology of cabbage butterfly, Pieris brassicae (L.), Lepidoptera: Pieridae on broccoli leaves in laboratory. Int J Pure Appl Biosci 6:12441251. https://doi.org/10.18782/2320-7051.5925

Denlinger DL, Lee J, Richard E (2010) Low temperature biology of insects. Cambridge University Press, Cambridge

Dicke M, Van Loon JJ, Soler R (2009) Chemical complexity of volatiles from plants induced by multiple attack. Nat Chem Biol 5:317

Driesche R (2008) Biological control of Pieris rapae in New England: host suppression and displacement of Cotesia glomerata by Cotesia rubecula (Hymenoptera: Braconidae). Fla Entomol 91:22-25. https://doi.org/10.1653/0015-4040(2008)091[0022: BCOPRI]2.0.CO;2

Egigu MC, Ibrahim MA, Yahya A, Holopainen JK (2010) Yeheb (Cordeauxia edulis) extract deters feeding and oviposition of Plutella xylostella and attracts its natural enemy. Biocontrol 55:613-624

Egigu MC, Ibrahim MA, Yahya A, Holopainen JK (2011) Cordeauxia edulis and Rhododendron tomentosum extracts disturb orientation and feeding behavior of Hylobius abietis and Phyllodecta laticollis. Entomol Exp Appl 138:162-174

Fatouros NE, Lucas-Barbosa D, Weldegergis BT, Pashalidou FG, van Loon JJA, Dicke M, Harvey JA, Gols R, Huigens ME, Bonaventure G (2012) Plant volatiles induced by herbivore egg deposition affect insects of different trophic levels (egg-induced plant volatiles affect community). PloS One 7:e43607. https://doi.org/ 10.1371/journal.pone.0043607

Feber R, Firbank L, Johnson P, Macdonald D (1997) The effects of organic farming on pest and non-pest butterfly abundance. Agric Ecosyst Environ 64:133-139

Girón-Calva PS, Li T, Blande JD (2016) Plant-plant interactions affect the susceptibility of plants to oviposition by pests but are disrupted by ozone pollution. Agric Ecosyst Environ 233:352-360. https://doi.org/10.1016/j.agee.2016.09.028

Harvey JA, Van Dam NM, Gols R (2003) Interactions over four trophic levels: foodplant quality affects development of a hyperparasitoid as mediated through a herbivore and its primary parasitoid. J Anim Ecol 72:520-531. https://doi.org/10.1046/j.1365-2656. 2003.00722.x
Hatano E, Saveer AM, Borrero-Echeverry F, Strauch M, Zakir A, Bengtsson M, Ignell R, Anderson P, Becher PG, Witzgall P (2015) A herbivore-induced plant volatile interferes with host plant and mate location in moths through suppression of olfactory signalling pathways. BMC Biol 13:75

Heil M (2014) Herbivore-induced plant volatiles: targets, perception and unanswered questions. New Phytol 204:297-306

Himanen SJ, Nerg A, Nissinen A, Pinto DM, Stewart CN, Poppy GM, Holopainen JK (2009) Effects of elevated carbon dioxide and ozone on volatile terpenoid emissions and multitrophic communication of transgenic insecticidal oilseed rape (Brassica napus). New Phytol 181:174-186

Himanen SJ, Blande JD, Klemola T, Pulkkinen J, Heijari J, Holopainen JK (2010) Birch (Betula spp.) leaves adsorb and re-release volatiles specific to neighbouring plants-a mechanism for associational herbivore resistance? New Phytol 186:722-732

Himanen SJ, Bui TNT, Maja MM, Holopainen JK (2015) Utilizing associational resistance for biocontrol: impacted by temperature, supported by indirect defence. BMC Ecol 15:16

Jaenson TG, Pålsson K, Borg-Karlson A (2005) Evaluation of extracts and oils of tick-repellent plants from Sweden. Med Vet Entomol 19:345-352

Jaenson TG, Pålsson K, Borg-Karlson A (2006) Evaluation of extracts and oils of mosquito (Diptera: Culicidae) repellent plants from Sweden and Guinea-Bissau. J Med Entomol 43:113-119

Jankowska B (2010) Effect of intercropping white cabbage with french marigold (Tagetes patula nana) and pot marigold (Calendula officinalis) on diamondback moth (Plutella xylostella 1.) population density and it's parasitoid complex. Veg Crops Res Bull 73:107-117

Joensuu J, Altimir N, Hakola H, Rostás M, Raivonen M, Vestenius M, Aaltonen H, Riederer M, Bäck J (2016) Role of needle surface waxes in dynamic exchange of mono- and sesquiterpenes. Atmos Chem Phys 16:7813. https://doi.org/10.5194/acp-16-7813-2016

Julkunen-Tiitto R, Nenadis N, Neugart S, Robson M, Agati G, Vepsäläinen J, Zipoli G, Nybakken L, Winkler B, Jansen MA (2015) Assessing the response of plant flavonoids to UV radiation: an overview of appropriate techniques. Phytochem Rev 14:273-297

Kalske A, Shiojiri K, Uesugi A, Sakata Y, Morrell K, Kessler A (2019) Insect herbivory selects for volatile-mediated plant-plant communication. Curr Biol 29:3128-3133.e3. https://doi.org/10.1016/j. cub.2019.08.011

Kessler A, Kalske A (2018) Plant secondary metabolite diversity and species interactions. Annu Rev Ecol Evol Syst 49:115

Khaling E, Papazian S, Poelman EH, Holopainen JK, Albrectsen BR, Blande JD (2015) Ozone affects growth and development of Pieris brassicae on the wild host plant Brassica nigra. Environ Pollut 199:119-129. https://doi.org/10.1016/j.envpol.2015.01.019

Khaling E, Li T, Holopainen JK, Blande JD (2016) Elevated ozone modulates herbivore-induced volatile emissions of Brassica nigra and alters a tritrophic interaction. J Chem Ecol 42:368-381

Li T, Blande JD (2015) Associational susceptibility in broccoli: mediated by plant volatiles, impeded by ozone. Glob Chang Biol 21:1993-2004

Loivamaki M, Mumm R, Dicke M, Schnitzler JP (2008) Isoprene interferes with the attraction of bodyguards by herbaceous plants. Proc Natl Acad Sci USA 105:17430-17435. https://doi.org/10.1073/ pnas.0804488105

Loreto F, Schnitzler J (2010) Abiotic stresses and induced BVOCs. Trends Plant Sci 15:154-166

Martijn Bezemer T, Harvey JA, Kamp AFD, Wagenaar R, Gols R, Kostenko O, Fortuna T, Engelkes T, Vet LEM, Der Putten V, Wim $\mathrm{H}$, Soler R (2010) Behaviour of male and female parasitoids in the field: influence of patch size, host density, and habitat complexity. Ecol Entomol 35:341-351. https://doi.org/10.1111/j.1365-2311. 2010.01184.x 
Mofikoya AO, Miura K, Ghimire RP, Blande JD, Kivimäenpää M, Holopainen T, Holopainen JK (2018a) Understorey Rhododendron tomentosum and leaf trichome density affect mountain birch VOC emissions in the subarctic. Sci Rep 8:1-12

Mofikoya AO, Kivimäenpää M, Blande JD, Holopainen JK (2018b) Ozone disrupts adsorption of Rhododendron tomentosum volatiles to neighbouring plant surfaces, but does not disturb herbivore repellency. Environ Pollut 240:775-780. https://doi.org/10.1016/j. envpol.2018.05.031

Mofikoya AO, Bui TNT, Kivimäenpää M, Holopainen JK, Himanen SJ, Blande JD (2019) Foliar behaviour of biogenic semi-volatiles: potential applications in sustainable pest management. ArthropodPlant Interact 13:193-212

Moreira X, Abdala-Roberts L, Gols R, Francisco M (2018) Plant domestication decreases both constitutive and induced chemical defences by direct selection against defensive traits. Sci Rep 8:1-11. https://doi.org/10.1038/s41598-018-31041-0

Niinemets Ü, Fares S, Harley P, Jardine KJ (2014) Bidirectional exchange of biogenic volatiles with vegetation: emission sources, reactions, breakdown and deposition. Plant Cell Environ 37:1790 1809. https://doi.org/10.1111/pce.12322

Ninkovic V, Dahlin I, Vucetic A, Petrovic-Obradovic O, Glinwood R, Webster B (2013) Volatile exchange between undamaged plantsa new mechanism affecting insect orientation in intercropping. PLoS One 8:e69431. https://doi.org/10.1371/journal.pone.00694 31

Noe S, Copolovici L, Niinemets Ü, Vaino E (2007) Foliar limonene uptake scales positively with leaf lipid content: "non-emitting" species absorb and release monoterpenes. Plant Biol 9:e79-e86

Onkokesung N, Reichelt M, van Doorn A, Schuurink RC, van Loon JJA, Dicke M (2014) Modulation of flavonoid metabolites in Arabidopsis thaliana through overexpression of the MYB75 transcription factor: role of kaempferol-3,7-dirhamnoside in resistance to the specialist insect herbivore Pieris brassicae. J Exp Bot 65:2203-2217. https://doi.org/10.1093/jxb/eru096

Ormeño E, Viros J, Mévy J, Tonetto A, Saunier A, Bousquet-Mélou A, Fernandez C (2020) Exogenous isoprene confers physiological benefits in a negligible isoprene emitter (Acer monspessulanum L.) under water deficit. Plants 9:159

Parolin P, Bresch C, Desneux N, Brun R, Bout A, Boll R, Poncet C (2012) Secondary plants used in biological control: a review. Int J Pest Manag 58:91-100

Pinto DM, Nerg A, Holopainen JK (2007) The role of ozone-reactive compounds, terpenes, and green leaf volatiles (GLVs), in the orientation of Cotesia plutellae. J Chem Ecol 33:2218-2228

Ponzio C, Gols R, Weldegergis BT, Dicke M (2014) Caterpillarinduced plant volatiles remain a reliable signal for foraging wasps during dual attack with a plant pathogen or non-host insect herbivore. Plant Cell Environ 37:1924-1935

Raal A, Orav A, Gretchushnikova T (2014) Composition of the essential oil of the Rhododendron tomentosum Harmaja from Estonia. Nat Prod Res 28:1091-1098

Rossiter M, Gershenzon J, Mabry TJ (1986) Behavioral and growth responses of specialist herbivore, Homoeosoma electellum, to major terpenoid of its host, Helianthus spp. J Chem Ecol 12:1505-1521

Rossiter JA, Kouvaritakis B, Rice MJ (1998) A numerically robust state-space approach to stable-predictive control strategies.
Automatica (Oxford) 34:65-73. https://doi.org/10.1016/S00051098(97)00171-4

Santonja M, Bousquet-Mélou A, Greff S, Ormeño E, Fernandez C (2019) Allelopathic effects of volatile organic compounds released from Pinus halepensis needles and roots. Ecol Evol 9:8201-8213

Schaub A, Blande JD, Graus M, Oksanen E, Holopainen JK, Hansel A (2010) Real-time monitoring of herbivore induced volatile emissions in the field. Physiol Plant 138:123-133. https://doi.org/10. 1111/j.1399-3054.2009.01322.x

Shiojiri K, Sabelis M, Takabayashi J (2015) Oviposition preference of cabbage white butterflies in the framework of costs and benefits of interspecific herbivore associations. R Soc Open Sci 2:150524. https://doi.org/10.1098/rsos.150524

Sontowski R, Gorringe NJ, Pencs S, Schedl A, Touw AJ, van Dam NM (2019) Same difference? Low and high glucosinolate varieties show similar responses upon feeding by two specialist root herbivores. Front Plant Sci 10:1451. https://doi.org/10.3389/fpls. 2019.01451

Stenberg JA, Heil M, Åhman I, Björkman C (2015) Optimizing crops for biocontrol of pests and disease. Trends Plant Sci 20:698-712. https://doi.org/10.1016/j.tplants.2015.08.007

Sukegawa S, Arimura G (2019) Two arrays of defense strategies of Brassicaceae plants that eavesdrop on mint volatiles. J Plant Interact 14:164-166

Sukekawa Y, Nakamoto T (2018) Odor biosensor system based on image lock-in measurement for odorant discrimination. IEEJ Trans SM 138:477-484. https://doi.org/10.1541/ieejsmas.138.477

Takabayashi J, Sato Y, Horikoshi M, Yamaoka R, Yano S, Ohsaki N, Dicke M (1998) Plant effects on parasitoid foraging: differences between two tritrophic systems. Biol Control 11:97-103

Talekar NS, Shelton AM (1993) Biology, ecology, and management of the diamondback moth. Annu Rev Entomol 38:275-301. https:// doi.org/10.1146/annurev.en.38.010193.001423

Tolosa TA, Tamiru A, Midega CAO, Van Den Berg J, Birkett MA, Woodcock CM, Bruce TJA, Kelemu S, Pickett JA, Khan ZR (2019) Molasses grass induces direct and indirect defense responses in neighbouring maize plants. J Chem Ecol 45:982. https://doi.org/10.1007/s10886-019-01122-z

Turlings TCJ, Tumlinson JH, Lewis WJ (1990) Exploitation of herbivore-induced plant odors by host-seeking parasitic wasps. Science 250:1251-1253. https://doi.org/10.1126/science.250.4985.1251

Wanner H, Gu H, Günther D, Hein S, Dorn S (2006) Tracing spatial distribution of parasitism in fields with flowering plant strips using stable isotope marking. Biol Control 39:240-247

Wink M (1988) Plant breeding: importance of plant secondary metabolites for protection against pathogens and herbivores. Theoret Appl Genet 75:225-233. https://doi.org/10.1007/BF00303957

Zhao Q, Ding Q, Yuan G, Xu F, Li B, Wang J, Ouyang J (2016) Comparison of the essential oil composition of wild Rhododendron tomentosum stems, leaves, and flowers in bloom and nonbloom periods from Northeast China. J Essent Oil Bear Plants 19:1216-1223

Publisher's Note Springer Nature remains neutral with regard to jurisdictional claims in published maps and institutional affiliations. 